\title{
Uma tão singular figura ${ }^{1}$
}

\author{
INOCÊNCIA MATA
}

Universidade de Lisboa

RESUMO: ALDA ESPÍRITO SANTO (1926-2010), UMA DAS MAIS IMPORTANTES POETISAS AFRICANAS, NASCEU NA ILHA DE SÃO TOMÉ. A SUA CAPACIDADE DE DIALOGAR COM SENSIBILIDADES CULTURAIS MUITO DIFERENTES, A SUA ATENÇÃO ÀS TRADIÇÕES E À (INEXISTÊNCIA DE UMA) POLÍTICA CULTURAL, O SEU CONSTANTE TRABALHO COM JOVENS E CRIANÇAS, ENFIM, A SUA POSTURA DE "ACTIVISTA CULTURAL" GRANJEARAM-LHE O ESTATUTO DE BASTONÁRIA DA DEFESA DOS VALORES CULTURAIS SÃO-TOMENSES.

ABSTRACT: ALDA ESPÍRITO SANTO (1926-2010), ONE OF THE MOST IMPORTANT AFRICAN FEMALE POETS, WAS BORN IN SÃO TOMÉ ISLAND. HER CAPACITY OF DIALOGUING WITH VERY DIFFERENT CULTURAL ENTITIES; HER ATTENTION TO TRADITIONS, AND TO THE (INEXISTENCE OF A) CULTURAL POLICY, BESIDES HER CONSTANT WORK WITH YOUTH AND CHILDREN, NAMELY, HER POSTURE AS A "CULTURAL ACTIVIST", ALL OF THESE CONFER HER THE STATUTE OF A NOTORIOUS DEFENSOR OF THE SÃO-TOMENSES CULTURAL VALUES.

PALAVRAS-CHAVE: ALDA ESPÍRITO SANTO, SÃO TOMÉ E PRÍNCIPE, CULTURA, POESIA. KEYWORDS: ALDA ESPÍRITO SANTO, SÃO TOMÉ E PRÍNCIPE, CULTURE, POETRY.

1 Versão aumentada do artigo do JL -Jornal de Letras, Artes Ideias (Lisboa), Março de 2010. 
uando, em 2002, Alda Espírito Santo publicou Mataram o Rio da Minha Cidade (três contos, crónicas de emigração e narrativas breves escritas para crianças, muito circunstanciais, num misto de prosa e poesia designada "Fabulário de recriação das ilhas"), todos pensaram que o rio a que a poetisa se referia era o Água Grande, o pequeno rio que atravessa a cidade capital do país - tão celebrado pelos poetas são-tomenses - depois de um acidentado percurso por montes e desfiladeiros, desaguando num estreito marginado por betão após estragos lendários devidos a cheias que se tornaram sóias na memória das gentes do interior. O tal Água Grande, que lhe inspirou o poema "Lá no Água Grande", já manso quando chega à cidade, não se compara ao rio vigoroso e indomável de onde provém, lá das terras de Mé Zóchi, numa confluência de várias "águas", uma das quais dá fulgor à turística Cascata de São Nicolau daí também a "mística" do rio.

\section{LÁ NO ÁGUA GRANDE}

Lá no "Água Grande” a caminho da roça negritas batem que batem co'a roupa na pedra.

Batem e cantam modinhas da terra.

Cantam e riem em riso de mofa

histórias contadas, arrastadas pelo vento.

Riem alto de rijo, com a roupa na pedra

e põem de branco a roupa lavada.

As crianças brincam e a água canta.

Brincam na água felizes...

Velam no capim um negrito pequenino.

E os gemidos cantados das negritas lá do rio

ficam mudos lá na hora do regresso ...

Jazem quedos no regresso para a roça.

Hoje, aquela paisagem humana cantada no poema, aparentemente celebrativo (se não descurarmos o final disfórico do poema), já não existe: no Água Grande, naquele lugar onde as lavadeiras costumavam lavar a sua roupa, dando à cidade um colorido singular, feito de histórias de vida, cânticos e gemidos, foi privatizado e, em vez de lavadeiras ou de mulheres na labuta quotidiana, 
existe um "centro comercial": o fervor neoliberal da "iniciativa privada" levou ao fechamento do acesso ao rio, transformando-o numa feira completamente caótica onde, à noite, raparigas também labutam oferecendo-se...

Alda Neves da Graça Espírito Santo nasceu na ilha de São Tomé (30 de Abril de 1926), onde fez os estudos primários. Como normalmente acontecia na época, entre os filhos da elite, cedo veio para a metrópole, para continuar o ensino liceal (em Vila Nova de Gaia e o $7^{\circ}$ ano em Lisboa). Diplomou-se na então Escola de Magistério Primário, também em Vila Nova de Gaia. Exerceu sempre em São Tomé e, por isso, foi professora de gerações sucessivas de são-tomenses que hoje, pela sua postura íntegra e inclusiva, se sentem, de certa forma, órfãos.

Por estes dias, em vários órgãos de comunicação africanos, muito se falou da representante da Geração de Cabral, expressão da lavra do angolano Mário Pinto de Andrade para designar o grupo de intelectuais africanos, jovens estudantes da Casa dos Estudantes do Império, como Amílcar Cabral, Maria Helena Vilhena Rodrigues (então esposa de Amílcar), Agostinho Neto, António Pimentel Domingues, Vasco Cabral, Agostinho Neto, o próprio Mário Pinto de Andrade, Viriato da Cruz, Francisco José Tenreiro, Guilherme do Espírito Santo, Marcelino dos Santos, Noémia de Sousa, entre muitos outros que, nos anos 50 do século XX, se reuniam na rua de Actor Vale, n 37, em Lisboa, a casa da Tia Andreza (onde vivia a Aldinha). Nesse local se constituiu o Centro de Estudos Africanos, uma espécie de centro de pesquisa onde era incentivado o gosto pelo conhecimento de África e que se transformaria em núcleo de germinação de ideias nacionalistas. De regresso definitivo ao seu país natal, continuou a assumir uma postura sempre incómoda quer no exercício da sua actividade docente, como professora do ensino primário, quer ainda como cidadã atenta à questão colonial (veja-se a perseguição de que foi vítima por ocasião do massacre do Batepá, em 1953).

Foi no convívio com esses jovens intelectuais, que farão a diferença na história de Portugal e das colónias portuguesas de África, numa altura em que a palavra podia ser um petardo demolidor do sistema, que Alda Espírito Santo encontrou na literatura um veículo de contestação. Com efeito, os seus primeiros poemas foram conhecidos em recitais e saraus entre 1946/47, só vindo a publicar em 1953, o poema "Lá no Água Grande", no caderno de Poesia Negra de Expressão Portuguesa, primeira manifestação sistémica da Negri- 
tude na África de língua portuguesa. Tratou-se de uma publicação organizada por Mário Pinto de Andrade, seu grande amigo, e Francisco José Tenreiro, outro dilecto são-tomense, autor de inúmeros estudos sobre a cultura negroafricana e afro-americana.

Embora não se possa considerar uma poetisa prolífera, tem inúmeros poemas dispersos em antologias e jornais nos quatro cantos do mundo e em várias línguas. Alguns desses poemas seriam reunidos, já depois da independência do seu país, em É nosso o Solo Sagrado da Terra - Poesia de Protesto e Luta (Lisboa: Ulmeiro, 1978). Já nos anos 2000, para além de Mataram o Rio da Minha Cidade, publicou O Coral das Ilhas (poesia, 2006) e Tempo Universal (poesia e prosa, 2008). Também fez incursões no ensaísmo, com artigos sobre o mundo cultural africano publicados, igualmente dispersamente, de que se destacam $A V$ z de S. Tomé (São Tomé, 1947) e Mensagem (boletim da Casa dos Estudantes do Império) e no jornal Revolução (São Tomé, 1975 - 1991). Mais recentemente contam-se publicações de textos resultantes de apresentação de livros e apontamentos cronísticos em trilogia publicada em 2006 - Mensagens do Solo Sagrado, Cantos do Solo Sagrado, Mensagens do Canto do Ossobó. Em 2006, por ocasião dos seus 80 anos foi publicado uma antologia dos seus poemas, contendo alguns poemas inéditos, em $A$ Poesia e a Vida: Homenagem a Alda Espírito Santo. ${ }^{2}$

Talvez se saiba muito sobre a escritora e a política, porém muito pouco sobre a cidadã participativa em que se tornou Alda Espírito Santo, após a abertura multipartidária, não obstante a sua intensa e definitiva vinculação ao MLSTP - Movimento de Libertação de São Tomé e Príncipe, partido único até 1991, de cujo governo fez parte várias vezes. Depois de 1991, ainda chegou a ser deputada numa legislatura, mas optou por retirar-se da política partidária activa. Embora extremamente desiludida nos últimos anos (repetia, desolada: "Não foi com isto que sonbámos"), Alda Espírito Santo não parava: ajudou a fundar e a manter, até à sua morte, a ULAJE-Clube UNESCO - União da Juventude de São Tomé e Príncipe (que funcionava na sede da UNEAS, de que era presidente), promoveu a criação do Fórum da Mulher Santomense, cooperativas de mulheres, grupos de teatro, incentivava o gosto pela leitura através de concursos literários. Era realmente uma figura suprapartidária e nacional.

2 MATA, Inocência; PADILHA, Laura. A Poesia e a Vida: Homenagem a Alda Espírito Santo. Lisboa: Edições Colibri, 2006. 
A sua capacidade de dialogar com sensibilidades culturais muito diferentes, a sua atenção às tradições e à (inexistência de uma) política cultural, o seu constante trabalho com jovens e crianças, enfim, a sua postura de "activista cultural" granjearam-lhe o estatuto de bastonária da defesa dos valores culturais são-tomenses: por exemplo, pugnou pela preservação da tradição dos passu glèra, isto é, os paços natalícios, construídos nos luchãs ${ }^{3}$, com materiais da terra (em vez de presépios importados e árvores de Natal - e até flocos de neve), através de concursos nacionais. A sua última batalha - a sua última grande tristeza! - foi o seu protesto contra a demolição extemporânea do monumento às vítimas do massacre de Batepá (03 de Fevereiro de 1953), na Praia de Fernão Dias, lugar emblemático desse evento (que ela denunciou em dois dos seus mais conhecidos poemas, "Trindade" e "Onde estão os homens caçados nesse vento de loucura"), para ser construído um hipotético "porto de águas profundas", "indispensável", diz a cartilha neoliberal, à economia do petróleo: um acto bárbaro, considerou ela no dia 03 de Fevereiro deste ano, um desrespeito pela memória das vítimas.

O sangue caindo em gotas na terra

homens morrendo no mato

e o sangue caindo, caindo ...

nas gentes lançadas no mar...

Fernão Dias para sempre na história

da Ilha Verde, rubra de sangue,

dos homens tombados

na arena imensa do cais.

Ai o cais, o sangue, os homens,

os grilhões, os golpes das pancadas

a soarem, a soarem, a soarem

caindo no silêncio das vidas tombadas

dos gritos, dos uivos de dor

dos homens que não são homens,

3 Quintais familiares, localidades clânicas do interior. 
na mão dos verdugos sem nome.

(...)

(“Onde estão os homens caçados nesse vento de loucura”.

(É Nosso o Solo Sagrado da Terra, 1978)

Estava furiosa, quase apopléctica. Alda Espírito Santo não conseguia acompanhar a lógica hegemónica da economia em detrimento de princípios.

É a essa metamorfose do espaço urbano, numa relação metonímica com a transformação do país, que a escritora se refere em Mataram o Rio da Minha Cidade... 